\title{
Identificarea stereotipurilor implicite privind rolul organizaţional atribuit femeilor şi bărbaţilor
}

\author{
Daniela Vercellino ${ }^{1}$ \\ Andrei lon \\ SNSPA - FCRP \\ Departament Psihologie
}

\begin{abstract}
The present paper investigated the way in which implicit gender stereotypes can influence the perception of female and male leaders within organisations. We created an experimental task based on Greenwald and Banaji's research (1995), methodology that is based on implicit associations. The present study was conducted on 81 participants, and the results were based on analyzing the reaction time and number of errors. The sampling process used the managerial level of the participants as criteria variable and we based our research on the three most common managerial levels: top, middle and low management, taking also into consideration the non-managerial levels. The results indicate that at non-managerial and low management level the implicit gender stereotypes continue to show some influences; instead, at top managerial level (where the important business decision are taken), implicit gender stereotypes does not influence the decision making process.
\end{abstract}

Keywords: gender stereotypes, management decisions, implicit associations

\section{Résumé}

La présente recherche se propose d'investiguer la modalité dans laquelle les stéréotypes inconscients peuvent influencer la perception de femmes et des hommes qui occupent des postions de management dans les organisations. Pour investigation presente on a construit une tâche expérimentale, basée sur les recherches de Greenwald \& Banaji (1995) recherches construites sur la méthode des associations implicites. L'échantillon utilisé est de 81 personnes et l'analyse a été réalisée en étudiant le temps de réaction et les erreurs de réponse. L'echantillonage a ete construit en partant des trois niveaux de management: le management superieur, le management moyen et le management de ligne, mais aussi le niveau non managerial. Les résultats indiquent que, même si, aux niveaux d'exécution et du management moyen, les différences de gendre se manifestent, en ce qui concerne les niveaux de management supérieur - qui prennent les décisions importantes pour les affaires, décisions avec une influence claire sur la politique de l'organisation, les stéréotypes implicites de gendre n'existent pas.

Mots-clés: stéréotypes de genre, décisions de management, associations implicites

\section{Rezumat}

Prezenta cercetare şi-a propus să investigheze modul în care stereotipurile de gen inconştiente pot influenţa percepţia femeilor şi bărbaţilor care ocupă poziţii de conducere în cadrul organizaţiilor. Pentru investigarea de faţă a fost construită o sarcină experimentală bazată pe cercetările lui Greenwald \& Banaji (1995) care are la bază metoda asocierilor implicite. Studiul a luat în calcul un eşantion de 81 de participanţi, iar analiza s-a realizat în baza timpului de reacţie şi a erorilor de răspuns. Eşantionarea a avut la bază segmentarea în funcţie de cele trei nivele de management: managementul de vârf, managementul de mijloc şi managementul de linie, precum şi nivelul non-managerial, cel de execuţie. Rezultatele obţinute indică faptul că la nivelul managementului de linie şi la nivelul non-managerial (de execuţie), stereotipurile de gen continuă să se manifeste, în timp ce la nivelul managementului de vârf (acolo unde se iau deciziile vitale pentru afacere), stereotipurile implicite nu se manifestă.

Cuvinte cheie: stereotipuri de gen, decizii de management, asociaţii implicite

\footnotetext{
${ }^{1}$ Adresa de corespondenţă: daniela.vercelino@comunicare.ro
} 


\section{Introducere}

Un cadru distinct de abordare a memoriei implicite este identificarea modului în care experienţele din trecut influenţează performanţa actuală, chiar dacă experienţa anterioară nu este reamintită în sensul uzual, adică nu este disponibilă prin raportare directă sau introspecţie (Graf \& Schacter, 1985; Jacoby \& Dallas, 1981; Jacoby, Lindsay, \& Toth, 1992; Jacoby \& Witherspoon, 1982; Roediger, Weldon, \& Challis, 1989; Schacter, 1987). Extinzând concluziile obţinute dincolo de memorie, Greenwald şi Banaji (1995) au identificat cogniţia socială implicită care apare atunci când experienţa trecută afectează / influenţează raţionamentul sau comportamentul social, dar natura acestei influenţe este imposibil de identificat prin introspecţie (sau cel puţin nu poate fi identificată în mod clar şi univoc) de către individ. $\mathrm{Ei}$ au oferit exemple de câteva fenomene de cogniţie socială implicită, focalizându-se pe studii în domeniul atitudinilor, stimei de sine şi stereotipurilor. În fiecare din aceste domenii, Greenwald şi Banaji (1995) au arătat cum comportamentul social operează într-un mod preponderent implicit sau inconştient. Aplicând definiţia cogniţiei sociale implicite în domeniul stereotipurilor, ei au definit stereotipurile implicite ca "experienţe anterioare imposibil de identificat prin introspecţie care mediază atribuirea calităţilor membrilor unei anumite categorii sociale" (Greenwald \& Banaji, 1995, p.182). Din punct de vedere teoretic, această abordare oferă o recunoaştere explicită a modului în care exprimarea de tip stereotip influenţează, în mod inconştient, judecata şi acţiunile şi posibila disociere dintre conştient şi inconştient în cadrul stereotipurilor. Din punct de vedere metodologic, implicaţiile acestei teorii sunt fundamentale. $\mathrm{O}$ astfel de definiţie subliniază rolul procesării inconştiente, ignorat anterior în măsurătorile clasice.

Premise teoretico-aplicative ale Testului Asocierilor Implicite (Implicite Association Test - IAT)

Interesul din ce în ce mai mare pentru procesele mentale inconştiente poate fi atribuit existenţei unor instrumente care permit măsurarea acestora. Măsurarea cogniţiilor implicite diferă de metoda auto-evaluării, prin faptul că acestea relevă asocieri mintale fără să necesite un act introspectiv (Banaji, 2001; Bargh, 1997; Fazio, Sanbonmatsu, Powell, \& Kardes, 1986; Greenwald \& Banaji, 1995; Wilson, Lindsey, \& Schooler, 2000). În ultimii ani, IAT (Greenwald, McGhee, \& Schwartz, 1998) a fost utilizat în studiul cogniţiei sociale implicite parţial, deoarece este uşor de implementat, mărimea efectului este mare şi dispune de 0 fidelitate satisfăcătoare (Greenwald \& Nosek, 2001). În ciuda popularităţii sale, există multe aspecte care nu sunt încă pe deplin explicate, cum ar fi: designul, analiza şi interpretarea efectelor IAT-ului. Multe studii de laborator arată multitudinea proceselor evidenţiate prin intermediul efectului IAT (Mierke \& Klauer, 2001; Rothermund, Wentura \& De Houwer, 2004), efectul caracteristicilor procedurale, cum sunt stimulii situaţionali (De Houwer, 2006; Steffens \& Plewe, 2001) şi stabilitatea temporală (Egloff \& Schmukle, 2004), relaţia dintre măsurătorile explicite şi implicite (Hofmann, Gawronski, Gschwendner, Le \& Schmitt, 2005; Nosek, 2004) şi maximizarea eficienţei procedurii de scorare (Greenwald, Nosek \& Banaji, 2003). Pe lângă înţelegerea naturii cogniţiei sociale implicite, aceste cercetări oferă recomandări pragmatice în virtutea maximizării eficienţei design-ului IAT. În cele ce urmează, vom prezenta modul în care a fost construit IAT-ul pentru studiul de faţă.

În baza principiilor teoriei învăţării şi reprezentării asociative, IAT-ul se bazează pe ipoteza că este mai uşor pentru cineva să practice acelaşi răspuns comportamental (apăsarea pe o tastă) pentru două concepte care sunt puternic asociate decât pentru conceptele slab asociate (Greenwald et al., 1998). Procedura IAT obligă respondenţii să identifice itemii stimuli şi să îi categorizeze în una sau patru categorii supraordonate. Puterea asocierii este măsurată prin compararea vitezei de categorizare a membrilor categoriei supraordonate în două condiţii de sortare diferite. De exemplu, deoarece în studiile realizate de Nosek, Greenwald şi Banaji (2005), conceptele "Bătrân" şi "Rău" tind să fie mai puternic asociate decât conceptele "Bătrân" şi "Bun", respondenţii sunt capabili să identifice şi să categorizeze itemii mai rapid în condiţiile în care itemii din categoria "Bătrân" şi "Rău" împărtăşeşc acelaşi răspuns comparat cu condiţia în care itemii din categoria "Bătrân" şi "Bun" împărtăşeşc acelaşi răspuns. 


\section{Obiective specifice}

1. Identificarea descriptorilor utilizaţi în descrierea liderului şi a managerului în cultura românească

2. Proiectarea unui Test de Evaluare a Atitudinilor Implicite pentru evaluarea rolului organizaţional - de lider sau subordonat

3. Identificarea rolului perceput al femeii - de manager sau subordonat - prin evaluarea stereotipurilor implicite faţă de femei

În vederea realizării celor trei obiective propuse, studiul cadru a fost structurat în două etapei; prima etapă a vizat identificarea acelor descriptori care sunt cel mai frecvent utilizaţi în descrierea celor două roluri cheie investigate de lider şi de subordonat; această etapă a fost necesară în vederea proiectării sarcinii IAT...

\section{Metodologia}

\section{Procedura de generare a stimulilor IAT}

În virtutea obţinerii cuvintelor care au fost incluse în cadrul IAT am recurs la două metode pentru cele două liste:

1. lista de cuvinte pentru bărbaţi şi femei a fost obţinută din studii anterioare realizate la nivel internaţional, inclusiv în România (Greenwald \& Banaji, 2005) cu IAT. Aceste cuvinte au fost distribuite după cum urmează:

:) Bărbat - fiul, unchiul, tata, nepotul

: Femeie - mama, fiica, nepoata, mătuşa

2. Pentru cea de-a doua listă de cuvinte, atribuite liderului/ şefului sau subordonatului s-a recurs la studiul literaturii de specialitate, încercând să se identifice acele caracteristici care îi diferenţiază pe lideri de subordonaţi. În acest sens, s-au identificat acele caracteristici care sunt asociate cu conducerea de succes şi, mai ales, cele care îi caracterizează doar pe lideri, nu şi pe subordonaţi (Bass, 1990; Kirkpatrick \& Locke, 1991). Astfel, au fost identificate 33 cuvinte, din care 16 caracteristici definitorii pentru lider şi 17 pentru subordonaţi. Aceste 33 cuvinte au fost puse sub forma unui chestionar care a fost aplicat unor participanţi, de la diferite nivele organizaţionale, cerându-li-se să noteze în dreptul fiecărui cuvând categoria din care face parte. Ca urmare a calculului frecvenţei fiecărui cuvânt, precum şi a realocării la categoria la care au fost plasate de către participanţi, s-a obţinut un număr de şase cuvinte, semnificative, pentru lider şi şase, pentru subordonat. Cuvintele obţinute au fost:

a) Lider - increzător, conduce, decide, energic, echilibrat, succes

b) Subordonat - ascultător, conformist, urmează, execută, docil, dependent

Pe baza cuvintelor de mai sus şi urmând regulile de construcţie a IAT-ului, a fost obţinută sarcina experimentală de evaluare a atitudinilor implicite.

\section{Proiectarea IAT}

Proiectarea IAT-ului pentru cercetarea de faţă a urmărit paşii sugeraţi de Greenwald şi Banaji (1995) şi anume:

Pasul 1. Învăţarea dimensiunii conceptuale. În prima fază, respondenţii sunt rugaţi să sorteze itemii celor două concepte în categoriile supraordonate. Categorizările sunt realizate prin folosirea a două taste " $A$ " şi " $L$ " care sunt plasate în dreptul categoriilor supraordonate şi itemii stimuli apar în mod secvenţial în mijlocul ecranului computerului.

Pasul 2. Învăţarea atributelor dimensiunii. În pasul 2, respondenţii realizează aceeaşi sarcină, utilizând aceleaşi două taste, dar de această dată sunt rugaţi să sorteze itemii care reprezintă cei doi poli ai dimensiunii.

Pasul 3. Perechea concept - atribut 1. În cel de-al treilea stadiu, aceste două sarcini de scorare sunt combinate astfel încât, prin încercări alternative, respondenţii să identifice un cuvând din supracategorie cu un cuvânt atribut. În acest pas, "A" este tasta pentru răspunsul corect la categoria "Bărbat şi Şef ", iar tasta "L" este răspunsul corect pentru cea de-a doua categorie "Femeie şi Subordonat".

Pasul 4. Schimbarea locaţiei spaţiale a conceptelor. În al patrulea pas, doar itemii stimuli pentru conceptul vizat (Şef şi Subordonat) sunt sortaţi pentru 20 de încercări dar, de data aceasta, sarcina este inversată. În exemplul nostru, itemii pentru "Femeie" vor $\mathrm{fi}$ pentru tasta "A", iar "Bărbat" pentru tasta "L".

Pasul 5. Perechea concept - atribut 2. În al cincilea pas, respondenţii sortează din nou itemii de la ambele atribute şi categoriile conceptului ţintă, cu menţiunea că, în acest pas, tasta "A" este pentru "Femeie şi Şef ", iar tasta "L" pentru "Bărbat şi Subordonat". (adică opus faţă de pasul 3). Respondenţii sortează 
itemii stimuli cu acest răspuns în 20 de încercări şi apoi din nou în 40 de încercări.

Efectul IAT este calculat realizând diferenţa dintre timpul de latenţă dintre Pasul 3 şi Pasul 5.

\section{Administrarea IAT}

Aplicarea sarcinii s-a făcut on-line, pe Internet, programul înregistrând automat timpul de reacţie, numărul şi tipul de erori făcute de fiecare subiect în parte. Sarcina a fost realizată cu sprijinul unei echipe de programatori care au fost instruiţi în privinţa funcţionalităţilor programului. Sarcina a fost creată astfel încât să poată fi vizualizată prin intermediul programului "Macro Media Flash 6".

Sarcina a fost completată sub protecţia anonimatului, participanţilor cerânduli-se să menţioneze doar date demografice legate de vârstă, gen şi nivelul organizaţional la care aceştia îşi desfăşoară activitatea. Timpul mediu de realizarea a sarcinii a fost cuprins în intervalul de $5-6$ minute.

\section{Participanți}

La studiu au participat 81 subiecţi, din mediul urban, cărora li s-a trimis spre completare un link (legătură) către un site de internet care conţinea programul de evaluare a atitudinilor implicite. Singura constrângere pentru participanţi a fost legată de efectuarea sarcinii fără întrerupere, programul blocânduse la întreruperi mai mari de 2 minute. Aspectele demografice ale eşantionului inclus în studiu sunt prezentate în Tabelele 1 şi 2 .

După cum se poate observa din analiza Tabelului 1 , vârsta minimă şi maximă asigură reprezentativitatea eşantionului.

Tabelul 1. Caracteristici demografice ale eşantionului din perspectiva vârstei

\begin{tabular}{|lccccc|}
\hline \multicolumn{1}{ll}{} & Nr. participanţi & $\begin{array}{c}\text { Vârsta } \\
\text { minimă }\end{array}$ & $\begin{array}{c}\text { Vârsta } \\
\text { maximă }\end{array}$ & Media & Abaterea standard \\
\hline Vârsta & 81 & 19.00 & 39.00 & 26.62 & 3.48 \\
\hline
\end{tabular}

Tabelul 2. Caracteristici demografice ale eşantionului

\begin{tabular}{llcc}
\hline \multirow{2}{*}{ Caracteristicile demografice } & $\begin{array}{c}\text { Număr } \\
\text { participanţi }\end{array}$ & $\begin{array}{c}\text { Frecvenţa exprimată în } \\
\text { procente }\end{array}$ \\
\hline Genul & Bărbaţi & 27 & $33.3 \%$ \\
& Femei & 51 & $63 \%$ \\
Valori absente & & 3 & $3.7 \%$ \\
\hline Nivelul & Executie & 32 & $39,5 \%$ \\
organizaţional & Management de linie & 12 & $14,8 \%$ \\
& Management de mijloc & 14 & $17,3 \%$ \\
& Management de vârf & 4 & $4,9 \%$ \\
Valori absente & Altele (studenţi, pensonari) & 16 & $19,8 \%$ \\
\hline Total participanţi & & 3 & $3,7 \%$ \\
\hline
\end{tabular}

Din punct de vedere al numărului de participanţi incluşi pe fiecare gen se poate observa că există un număr uşor mai mare de femei care au completat sarcina experimentală.

Din analiza Tabelului 2 putem observa că eşantionul prezintă o anumită disproporţie între nivelele de management şi cele de execuţie, însă această discrepanţă este uzuală la nivel organizaţional, unde managementul reprezintă un procent mic faţă de nivelul de execuţie.

\section{Rezultate şi discuţii}

Datele obţinute au fost supuse unor analize comparative, având la bază principiile stabilite de Greenwald, Nosek şi Banaji (2005). Categoriile vizate pentru analiză au fost categoria 3 (şef femeie - subordonat bărbat) şi categoria 4 (şef bărbat - subordonat femeie), 
cu menţiunea că prima categorie încearcă spargerea stereotipului, iar cea de-a doua reflectă confirmarea acestuia. Timpii de reacţie au fost analizaţi din punct de vedere al distribuţiei Datorită distribuţiei simetrice a datelor, s-a calculat diferenţa dintre medii, prin testul t pe eşantioane perechi.

Tabelul 3

Testul t pe eşantioane perechi pentru categoriile prostereotip şi contrastereotip

\begin{tabular}{ccccccc}
\hline Categorii & Media & $\begin{array}{c}\text { Abaterea } \\
\text { standard }\end{array}$ & Media & $\begin{array}{c}\text { Abaterea } \\
\text { standard }\end{array}$ & $\begin{array}{c}\text { Valoarea } \\
\text { testului "t" }\end{array}$ & $\mathrm{p}$ \\
\hline $\begin{array}{c}\text { Pro-stereotip (categoria 4) } \\
\text { Contra-stereotip (categoria }\end{array}$ & 1.49 & .38 & & & & \\
3) & 1.32 & .29 & .1658 & .27112 & 4.69 & .000 \\
\end{tabular}

Tabelul 4. Testul t pe eşantioane perechi pentru categorii identice dar spaţial opuse

\begin{tabular}{ccccccc}
\hline Categorii & Media & $\begin{array}{c}\text { Abaterea } \\
\text { standard }\end{array}$ & Media & $\begin{array}{c}\text { Abaterea } \\
\text { standard }\end{array}$ & $\begin{array}{c}\text { Valoarea } \\
\text { testului t }\end{array}$ & $\mathrm{p}$ \\
\hline $\begin{array}{c}\text { Pro-stereotip (localizat } \\
\text { spaţial stânga) }\end{array}$ & 1.32 & .26 & & & & \\
$\begin{array}{c}\text { Pro-stereotip (localizat } \\
\text { spaţial dreapta) }\end{array}$ & 1.38 & .64 & .05 & .60 & .84 & .402 \\
\hline
\end{tabular}

Tabelul 5. Testul t pe eşantioane perechi pe eşantionul de bărbaţi

\begin{tabular}{ccccccc}
\hline Categorii & Media & $\begin{array}{c}\text { Abaterea } \\
\text { standard }\end{array}$ & Media & $\begin{array}{c}\text { Abaterea } \\
\text { standard }\end{array}$ & $\begin{array}{c}\text { Valoarea } \\
\text { testului t }\end{array}$ & $p$ \\
\hline Pro-stereotip & 1.54 & .38 & & & & \\
Contra - stereotip & 1.52 & .20 & .21 & .28 & 3.87 & .001 \\
\hline
\end{tabular}

Tabelul 6. Testul t pe eşantioane perechi pe eşantionul de femei

\begin{tabular}{ccccccc}
\hline Categorii & Media & $\begin{array}{c}\text { Abaterea } \\
\text { standard }\end{array}$ & Media & $\begin{array}{c}\text { Abaterea } \\
\text { standard }\end{array}$ & $\begin{array}{c}\text { Valoarea } \\
\text { testului t }\end{array}$ & $\mathrm{p}$ \\
\hline Pro - stereotip & 1.46 & .34 & & & & \\
Contra - stereotip & 1.33 & .29 & .13 & .25 & 3.83 & .000 \\
\hline
\end{tabular}

După cum se poate observa în Tabelul 3, apar diferenţe semnificative statistic între cele două categorii vizate de studiul implicit. Timpul de reacţie în categoria contra-stereotip (şef femeie - subordonat bărbat) - în care participanţii trebuie să aloce cuvintele pentru categoria care merge împotriva stereotipului este mai mare decât timpul de reacţie din categoria pro-stereotip (şef bărbat subordonat femeie), ceea ce indică prezenţa stereotipului - în care participanţii trebuie să aloce cuvintele referitoare la şef sau lider pentru categoria care susţine stereotipul social, conform căreia femeile se regăsesc mai degrabă în poziţii de subordonare, iar bărbaţii se regăsesc mai frecvent în poziţii de conducere.

Pentru a vedea în ce măsură efectul poziţiei spaţiale (stânga versus dreapta) a influenţat rezultatele obţinute, categoria şef bărbat - subordonat femeie a fost repetată dar cu schimbarea spaţială a categoriilor, adică subordonat femeie - şef bărbat. În acest sens, au fost comparate rezultatele obţinute la 
această categorie cu categoria identică, dar diametral opusă spaţial, pentru a observa impactul a ceea ce poate fi considerată o variabilă care poate interfera cu rezultatele reale.

Din analiza Tabelului 4 rezultă că nu apar diferenţe în timpul de reacţie al participanţilor atunci când categoriile identice sunt locate spaţial diferit. Astfel, se poate afirma că efectul poziţiei nu este o variabilă care să influenţeze în mod semnificativ şi evident rezultatele obţinute în cadrul acestei probe experimentale. Acest lucru ne permite să afirmăm că rezultatele obţinute la cele două categorii diferite conceptual - pro şi contra stereotip - sunt valide şi corect interpretate ca diferenţe semnificative datorate stereotipurilor sociale de gen, care consideră că femeile sunt percepute a fi mai apropiate rolului de subordonat decât rolului de manager, în timp ce bărbaţii sunt percepuţi ca fiind mai apropiaţi rolului de manager decât femeile.

Pentru o analiză mai de profunzime, sa încercat evaluarea modului în care aceste stereotipuri implicite se manifestă în mod diferit la femei şi bărbaţi, în sensul în care această diferenţă ar trebui să fie mai mică pentru femei. Tabelele 5 şi 6 arată modul în care femeile şi bărbaţi se raportează la aceste stereotipuri.

După cum se poate observa din analiza Tabelului 5, există diferenţe semnificative în alocarea cuvintelor în categoriile pro şi contra stereotip. În acest sens, putem afirma că bărbaţii dispun de stereotipuri sociale de gen.

Din analiza Tabelului 6 rezultă, în mod clar, că femeile deţin stereotipuri implicite la fel de pregnante ca şi cele ale bărbaţilor. După cum se poate observa, valoarea testului t este apropiată, ceea ce indică că diferenţa mediilor este asemănătoare şi, mai ales, este în aceeaşi direcţie, adică cea a stereotipizării.

Tot cu scopul de a rafina cercetarea, s-a recurs la analiza datelor obţinute în funcţie de nivelul organizaţional ocupat de participanţii la studiu. Rezultatele acestei analize sunt prezentate în cele ce urmează.

Tabelul 7. Testul t pe eşantioane perechi în funcţie de nivelul organizaţional

\begin{tabular}{cccccc}
\hline & Nr. participanţi & Media & $\begin{array}{c}\text { Abaterea } \\
\text { standard }\end{array}$ & $\begin{array}{c}\text { Valoarea } \\
\text { testului t }\end{array}$ & $\mathrm{p}$ \\
\hline Nivel organizaţional & 32 & 1.44 & .37 & 3.92 & .000 \\
Execuţie & 12 & 1.48 & .27 & 2.45 & .032 \\
Management de linie & 14 & 1.44 & .30 & 1.59 & .135 \\
Management de mijloc & 4 & 1.51 & .24 & .30 & .779 \\
Altele & 16 & 1.62 & .43 & 2.71 & .016 \\
\hline
\end{tabular}

Din analiza Tabelului 7 se poate constata că, la nivel de management de mijloc şi de vârf, diferenţele nu sunt semnificative, ceea ce înseamnă că stereotipurile implicite de gen nu acţionează (sau acţionează într-o măsură mult mai redusă) la acest nivel. Analiza nivelelor superioare ale managementului ne va furniza însă o viziune de ansamblu în privinţa modului în care aceste stereotipuri acţionează la nivelul funcţiilor manageriale organizaţionale.

Se poate observa că diferenţele sunt în totalitate estompate, adică la nivelul managemetului de vârf, acolo unde sunt luate decizii importante, decizii cu influenţa clară asupra politicilor organizaţionale, stereotipurile implicite de gen nu există. Din analiza stereotipurilor implicite la cele patru nivele organizaţionale, se poate concluziona că, pe măsură ce urcăm în ierarhia organizaţională, stereotipurile tind să se estompeze pâna la suprimarea lor, dacă nu chiar la dispariţia lor. Acest fenomen este explicabil prin aceea că, la astfel de nivele organizaţionale, decizia tinde să devină din ce în ce mai raţională şi mai axată pe fapte concrete, obiective şi, mai ales, cu accent pe profitabilitate, care ocupă un loc primordial, chiar şi în faţa normelor şi valorilor sociale generale.

Deşi cercetările în domeniul stereotipurilor au utilizat de cele mai multe ori metode explicite sau directe (Judd \& Park, 1993), există destul de multe cercetări care evidenţiază beneficiile măsurătorilor indirecte sau implicite. Deşi utilizarea măsurătorilor implicite, în majoritatea studiilor, reflectă de 
cele mai multe ori intenţia cercetătorilor de a evita apariţia efectului managementului impresiei, ca variabilă - eroare, cercetarea de faţă a fost realizată pentru a măsura, în mod special, modul în care stereotipurile operează la nivel inconştient. Rezultatele acestei cercetări sugerează că, de cele mai multe ori, stereotipurile de gen sunt exprimate comportamental într-o formă implicită.

Aşa cum arată şi cercetările din ultimele decenii, cea mai mare parte a cogniţiei sociale are loc în mod implicit. Aceste concluzii derivă din reinterpretarea rezultatelor, care relevă importanţa modului implicit în care acţionează atitudinile şi, mai ales, stereotipurile de gen. Aşa cum se poate observa şi din studiul de faţă, majoritatea indivizilor femei şi bărbaţi prezintă stereotipuri de gen privind modul în care percep femeile şi anume ca fiind mai apropiate rolului de subordonat decât rolului de lider. Raportând această idee la teoria congruenţei rolului (Eagly \& Johannesen-Schmidt, 2001), care afirmă importanţa conţinutului rolului de gen în promovarea diferenţelor de gen (Eagly \& Johannesen-Schmidt, 2001), se poate constata că potenţialul pentru discriminarea femeilor manager - discriminare inerentă pentru femei datorită disimilarităţii faţă de aşteptările pe care indivizii le au grupate în jurul unui prototip despre lideri - este mai mare decât cea faţă de bărbaţi. Prejudecata şi discriminarea subtilă aferentă apare atunci când indivizii judecă femeile ca potenţiale ocupante ale unor roluri de conducere. Această reacţie se datorează inconsistenţei dintre femei - care sunt percepute ca având mai degrabă caracteristici feminine - şi rolul de conducere - conturat preponderent din caracteristici masculine.

Un aspect pozitiv care, trebuie punctat, prin prisma rezultatelor obţinute, este că stereotipurile sunt menţinute şi perpetuate mai ales de ocupanţii nivelului de execuţie şi mai puţin de ocupanţii nivelelor de management. O posibilă concluzie este că, la nivelul ocupanţilor poziţiilor de management, aspectul care face diferenţa perceptuală şi comportamentală la nivel de stereotip de gen este axarea lui pe alte norme şi valori, care depind mai mult de eficienţa organizaţională şi de profitul aferent şi mai puţin de conformarea la normele şi valorile social împărtăşite.

\section{Concluzii}

În pofida influenţei rolului de gen în situaţii şi, mai ales, în decizii organizaţionale, se poate afirma că există dovezi clare conform cărora femeile se conformează cerinţelor impuse de rolul de lider, restricţionând într-o anumită măsură inferenţele datorate stereotipurilor de gen. În această situaţie, datele obţinute în experimentul de faţă sunt consecvente cu ideea prezentată. Rolul de gen are o valoare importantă, modelează comportamentul indivizilor, mai mult într-o măsură implicită, exercitând $\quad 0$ influenţă indirectă, de multe ori slab observabilă şi cu atât mai puţin identificabilă prin măsurători explicite. În acest sens, posibilitatea de a identifica, prin cercetare implicită, stereotipurile de gen, rămâne o soluţie viabilă. Luând în considerare că acestea, prin natura lor implicită, determină o reacţie de multe ori subtilă sau mascată pot avea consecinţe asupra deciziilor organizaţionale, cum ar fi în sfera selecţiei sau promovării unei femei într-o funç̧ie de management, mai ales de vârf, datorită faptului că procesul de recrutare selecţie este realizat de persoane care ocupă nivele de execuţie.

Ceea ce se poate concluziona este că IAT-ul este un instrument cu mare potenţial în identificarea stereotipurilor de gen implicite, a acelor stereotipuri care afectează în mod subtil şi nespecificat percepţia femeilor - manager. După cum s-a observat, cel mai mare potenţial de perpetuare a stereotipurilor se află la nivelul organizaţional de execuţie. Cu toate acestea, şi aici există mari pericole de a pune bariere în dezvoltarea, promovarea sau selecţia unei femei pe o pozitiie de conducere, deoarece cei responsabili cu selecţia resurselor umane sau cu dezvoltarea planurilor de carieră nu sunt întotdeauna poziţionaţi pe nivele de management şi, prin urmare, sunt, în baza rezultatelor acestui studiu, mai puternic influenţaţi de stereotipuri de gen.

\section{Bibliografie}

Banaji, M. R., \& Greenwald, A. G. (1995). Implicit gender stereotyping in judgment frames. Journal of Personality and Social Psychology, 68(2), 181-198.

Banaji, M. R. (2001). Implicit attitudes can be measured. In H. L. Roediger, III, J. S. Nairne, I. Neath, \& A. Surprenant (Eds.), The nature of remembering: Essays in 
honor of Robert G. Crowder (pp. 117-150). Washington, DC: American Psychological Association.

Bargh, J. A. (1997). The automaticity of everyday life. In R. S. Wyer, Jr. (Ed.), The automaticity of everyday life: Advances in social cognition (Vol. 10, pp. 1-61). Mahwah, NJ: Erlbaum.

Bass, B. M. (1990). From transactional to transformational leadership: Learning to share the vision. Organizational Dynamics, 18 (3): 19-31

De Houwer, J. (2006). What are implicit measures and why are we using them? In R. W. Wiers \& A. W. Stacy (Eds.), The handbook of implicit cognition and addiction (pp. 11-28). Thousand Oaks, CA: Sage.

Eagly, A. H. \& Johannesen-Schmidt, M. C. (2001) The Leadership Styles of Women and Men Journal of Social Issues, 57, 781-797

Egloff, B. \& Schmukle, S. C. (2004). Gender differences in implicit and explicit anxiety measures. Personality and Individual Differences, 36, 1807-1815

Fazio, Russell H., David M. Sanbonmatsu, Martha C. Powell, and Frank R. Kardes. (1986). "On the Automatic Activation of Attitudes," Journal of Personality and Social Psychology, 50, 229-238.

Graf, P. \& Schacter, D.L. (1985). Implicit and explicit memory for new associations in normal and amnesic subjects. Journal of Experimental Psychology: Learning, Memory, and Cognition, 11, 501-518

Greenwald, A. G., Nosek, B. A., Banaji, M. R., \& Klauer, K. C. (2005). Validity of the salience asymmetry interpretation of the IAT: Comment on Rothermund, Wentura \& De Houwer (2004). Journal of Experimental Psychology: General, 134, 420-425

Greenwald, A. G., Nosek, B. A., \& Banaji, M. R. (2003). Understanding and Using the Implicit Association Test: I. An Improved Scoring Algorithm. Journal of Personality and Social Psychology, 85, 197-216

Greenwald, A. G., \& Nosek, B. A. (2001). Health of the Implicit Association Test at age 3. Zeitschrift für Experimentelle Psychologie, 48, 85-93.

Greenwald, A. G., Banaji, M. R., Rudman, L. A., Farnham, S. D., Nosek, B. A., \& Rosier, M. (2000). Prologue to a unified theory of attitudes, stereotypes, and self-concept. In J. Forgas (Ed.) The role of affect in social cognition (pp. 308-330). Cambridge, UK: Cambridge University Press.
Greenwald, A. G., \& Farnham, S. D. (2000). Using the Implicit Association Test to measure self-esteem and self-concept. Journal of Personality and Social Psychology, 79(6), 1022-1038.

Greenwald, A. G., McGhee, D. E., \& Schwartz, J. K. L. (1998). Measuring individual differences in implicit cognition: The Implicit Association Test. Journal of Personality and Social Psychology, 74, 1464-1480

Greenwald, A. G., \& Banaji, M. R. (1995). Implicit social cognition: Attitudes, self-esteem, and stereotypes. Psychological Review, 102(1), 4-27.

Hofmann, W., Gawronski, B., Gschwendner, T., Le, H., \& Schmitt, M. (2005). A meta-analysis on the correlation between the Implicit Association Test and explicit self-report measures. Personality and Social Psychology Bulletin, 31, 1369-1385

Jacoby, L. L., Lindsay, D. S., \& Toth, J. P. (1992). Unconscious influences revealed: Attention, awareness, and control. American Psychologist, 47, 802-809.

Jacoby, L.L. \& Dallas, M. (1981). On the relationship between autobiographical and perceptual learning. Journal of Experimental Psychology: General, 110, 306-340.

Jacob L. L., \& Witherspoon, D. (1982). Remembering without awareness. Canadian Journal of Psycholog£, 32, 300-324.

Judd, C. M. \& Park, B. (1993). Definition and assessment of accuracy in social stereotypes. Psychological Review, 100, 109-128.

Kirkpatrick, S. \& Locke, E. 1991. Leadership: Do traits matter? Academy of Management Executive, 5 (2), 48-60.

Mierke, J., \& Klauer, K. C. (2001). Implicit association measurement with the IAT: Evidence for effects of executive control processes. Zeitschrift für Experimentelle Psychologie, 48, 107-122.

Nosek, B. A. (2004). Moderators of the relationship between implicit and explicit attitudes. Unpublished manuscript, University of Virginia, Charlottesville

Roediger, H.L., Weldon, M.S., \& Challis, B.H. (1989). Explaining dissociations between implicit and explicit measures of retention: $A$ processing account. Chapter in H.L. Roediger \& F.I.M. Craik (Eds.), Varieties of memory and consciousness: Essays in honour of Endel Tulving. (p. 3-39). Hillsdale, $\mathrm{NJ}$ : Erlbaum.

Rothermund, K., Wentura, D. \& De Houwer (2004). Validity of the Salience Asymmetry Account 
of the Implicit Association Test: Reply to Greenwald, Nosek, Banaji, and Klauer (2005). Journal of Experimental Psychology: General, 134 (3), 426-430

Schacter, D. L., Implicit Memory: History and Current Status. Journal of Experimental Psychology: Learning, Memory, and Cognition, 13,(3). 501-518
Steffens, Melanie C. and Inga Plewe (2001), Items' Cross-Category Associations as a Confounding Factor in the Implicit Association Test, Zeitschrift fuer Experimentelle Psychologie, 48 (2), 123-34.

Wilson, T. D., Lindsey, S., \& Schooler, T. Y. (2000). A model of dual attitudes. Psychological Review, 107, 101-126

\section{Anexa 1}

Exemplu din sarcina experimentală de evaluare a stereotipurilor implicite

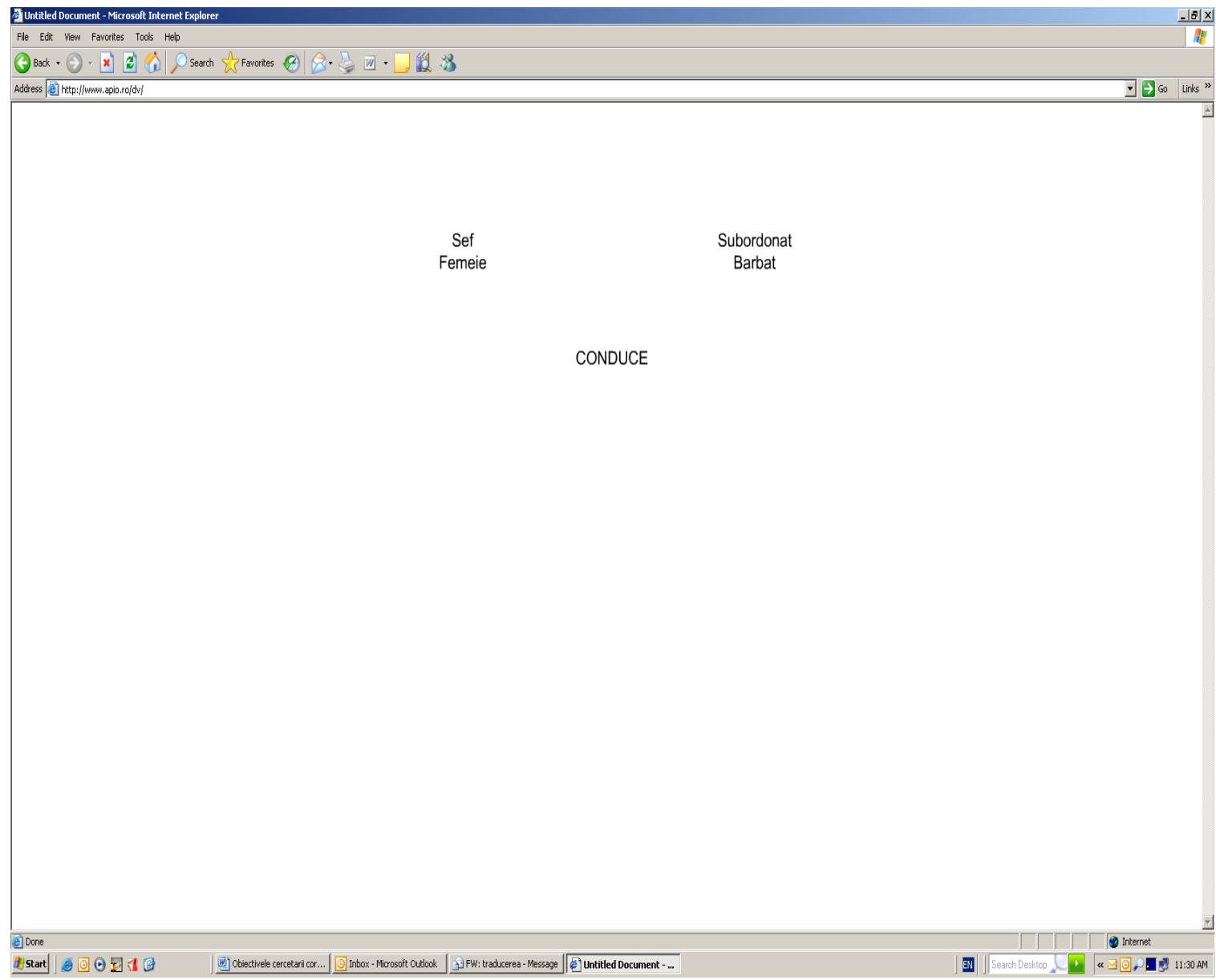

